\title{
Comparison of Maitland Thoracic Spine Manipulation Versus Maitland Cervical Spine Mobilization in Chronic Unilateral $\mathbf{C}_{6}-$ $\mathrm{C}_{7}$ Cervical Radiculopathy
}

\author{
Shoaib Waqas, ${ }^{1}$ Ashfaq Ahmad, ${ }^{2}$ Shahzad Ahmad, ${ }^{3}$ Tariq Shafi, ${ }^{4}$ Hassan Anjum Shahid ${ }^{5}$
}

\begin{abstract}
Background: Radicular pains are very common in cervical region due to $\mathrm{C}_{6}-\mathrm{C}_{7}$ nerve root involvement which results discomfort and restriction of mobility of upper and lower segments of cervical and thoracic spine. A lot of evidences about non-operative treatments have been derived for managing cervical radiculopathies with a little documentation of manual the-

Date of Submission 7-11-2015

Date of Revision Received 29-2-2016

Date of Acceptance for Publication 2-4-2016

Conflict of Interest: None

Funding Source: None
\end{abstract}

Waqas $\mathrm{S}^{1}$

Physiotherapy Lecturer, University Institute of Physical

Therapy, The University of Lahore, Pakistan

Ahmad A. ${ }^{2}$

Assistant Professor/HOD of Physiotherapy Department

The University of Lahore, Pakistan

Ahmad S. ${ }^{3}$

Physiotherapy Senior lecturer at LMDC, Pakistan

Shafi T. ${ }^{4}$

Physiotherapist at Shalamar Hospital, Lahore

Shahid H.A. ${ }^{5}$

Assistant Professor / HOD Physiotherapy Department Imperial University Lahore, Pakistan rapy. So, in this study, Maitland concept of manipulation and mobilization at two different regions of spine (thoracic and cervical) respectively, was used to see the change in pain reduction and restoration of normal functional abilities.

Methodology: A study design of Comparative single blinded, randomized control clinical trials was used. 100 patients having chronic unilateral $\mathrm{C}_{6}-\mathrm{C}_{7}$ cervical radiculopathy's symptoms due to disc prolapsed, divided into two groups with simple random sampling as guided per-consolidated standards of reporting trials (CONSORT) guidelines were used. First group was managed with Maitland thoracic spine manipulation (MTSM), mechanical intermittent cervical traction (MICT) for 10 minutes and regime of strengthening exercises (SE) and second group was managed with Maitland cervical spine mobilization (MCSM), MICT and SE. The duration of treatment was four weeks at the rate of three times in one week. Two outcome measures numeric pain rating scale (NPRS) and Neck disability index (NDI) questionnaire were used for evaluation and investigation. Data was collected at start, after two and after four Weeks's treatment. Independent $\mathrm{T}$ test with extension of Levene's test was used with $0.05 \%$ level of confidence.

Results: The calculated $p$ value for NPRS and NDI for group A (MTSM) was $\mathrm{P}=0.000$ which was less than 0.05 having validation of significant changes. So, we reject our Null hypothesis that MTSM is more effective than MCSM.

Conclusion: The result shows that MTSM and MCSM were effective techniques for pain reduction and functional abilities restoration. However, the subjects of first group with MTSM, MICT and SE presented better progress in reduction of neck ache and refining 
functional status during comparison.

Keywords: Maitland Cervical Spine Mobilization, Maitland Thoracic Spine Manipulation, Unilateral Cervical Radiculopathy, Mechanical Cervical Traction and Strengthening Exercises.

\section{Introduction}

Musculoskeletal pains are very common in society and it mainly includes the pains of back, neck and shoulder. Pain in the cervical region is the second most common disability, while mechanical back ache is the leading one. ${ }^{1}$ The rate of neck pain is continuously rising, due to sedentary life style and especially dependence on computer and laptops at the workplace. Mostly cervical radiculopathy (CR) presents as pain in the neck region, resulting in marked uneasiness and inability to perform various functions normally. ${ }^{2}$

CR accounts for five to thirty six percent of all the radiculopathies. The incidence rate of $\mathrm{CR}$ is at 83.2 cases per 100,000 people. The prevalence rate of CR is $3.5 / 1000$ persons. $^{3}$

The presenting complaints of CR differ greatly on account of the roots of spinal nerves involved. Patient generally presents with discomfort disturbed sensateions and significant loss of muscle strength in upper limb causing functional limitations. ${ }^{4}$ In $\mathrm{C}_{6}$ radiculopathy, weakness occurs in elbow flexors, wrist extensors and brachioradialis muscle with pain and sensory loss while in $\mathrm{C}_{7}$ radiculopathy, loss of muscle strength of all extensors of upper limb with discomfort and disturbed sensation occurs. ${ }^{5}$

According to the existing literature, the leading cause of CR is cervical disc herniationas in 2013, Gopal Nambi et al, conducted a study to see the effects of cervical spine mobilization (CSM) and thoracic spine manipulation (TSM), with intermittent cervical traction and strengthening regime in patients of chronic unilateral $\mathrm{C}_{6}-\mathrm{C}_{7}$ cervical radiculopathy. After study, they concluded that both mobilizations and manipulations are effective for such patients but TSM having better results than CSM with controlled protocols. ${ }^{6}$

In 2013 Kaur Inderpreet et al, conducted a study to determine the effects of Maitland verses Mulligan mobilization technique on subjects of neck ache at upper thoracic region. The study results showed that Maitland mobilization along with the conventional treatment prove to be more effective in improving functional status and pain with nonspecific neck ache than second treatment. ${ }^{7}$ In 2012, Rodine and Vernon con- ducted a systemic review on effects of spinal manipulation treatment for cervical radiculopathy (CR) and measurement with the neck disability index. This review suggests that spinal manipulation can be used therapeutically for the management of cervical radiculopathy but with a lot of precautionary measures. It was found that this manipulative treatment is well suited for $\mathrm{CR}^{8}$

In 2012, Jiang et al conducted a study to see the effects of traction. It was a comparison between cervical fixed point traction and cervical computer traction. They concluded that cervical manual traction having more beneficial results than computerized cervical traction for treatment of CR. ${ }^{9}$ In 2011, Boyles et al, did a study to comprehend the efficacy of manual physical therapy for management of CR. They came to the conclusion that manual physiotherapy combined with carefully prescribed exercises are beneficial in enhancing functional activity as well as active range of motion (AROM) while decreasing the level of pain and disability. ${ }^{10}$

All work which had been done for the management of cervical radiculopathies was manual therapy including spinal mobilizations and manipulations, intermittent cervical tractions, strengthening regimes and postural cares. The thing which was not foundin the existing literature was thenon - availability of specific technique of manual therapy of well renowned manual therapists such as Maitland, Mulligan or Cyriax for management of cervical radiculopathy. I want to see and compare some specialized techniques of Maitland mobilizations and manipulations for the management of chronic unilateral cervical radiculopathies.

Rationale of this study is to find out are search based selection of most authentic management regime for the subjects of chronic unilateral $\mathrm{C}_{6}-\mathrm{C}_{7}$ cervical radiculopathy. We had been concentrated on the comparative efficacy of manual management patterns concepts which was ignored earlier and having deficiencies in existing literature. So it could be helpful for both physical therapists as well as patients.

\section{Material and Methods}

Study Design: Comparative single blinded, randomized control clinical trials.

Sampling Technique: Simple random sampling technique as guided per CONSORT guidelines.

Sample Size: A data of 100 patients was collected. 
Settings: Physiotherapy Department National Hospital and Medical Center DHA Lahore

Methodology: We divided 100 patients into two groups. Group 1 was treated with (MTSM, MICT and SE) and group 2 with (MCSM, MICT and SE). Both male and female Patients of twenty one years to sixty years, all referred patients by orthopedic or neurosurgeon having chronic $\mathrm{C}_{6}-\mathrm{C}_{7} \mathrm{UCR}$ (due to cervical disc prolapsed) and patients with positives purling test, upper limb tension test (ULTT), cervical distraction test and provocation test was included in study. ${ }^{11}$ All other patients with $\mathrm{C}_{6}-\mathrm{C}_{7}$ Unilateral Cervical radiculopathy due to any other cause rather than disc prolapsed, red flags signs, any history of MSK problems, CNS and cardiac issues, history of trauma and progressive neurological deficit, bilateral upper extremity radicular symptoms were include or excluded. ${ }^{12}$ Diagnosis of cervical spine stenosis and any surgical history to cervical spine or thoracic spine and involved upper limb was excluded. ${ }^{13}$

Hundred patients who fulfilled the selection criteria were enrolled in the study after taking written informed consent from each individual. Both groups received mechanical intermittent cervical traction for 10 minutes and strengthening exercises for neck musculature which remained same through out of study. Group A received Maitland thoracic spine manipulation technique and Group B received Maitland cervical spine mobilization technique with combined therapy $(\mathrm{MICT}+\mathrm{SE})$ respectively.

Each group was treated thrice a week for one month (four weeks). Subjects were checked at the start of treatment, at the end of second week and at 4th week by using Numeric Pain Rating Scale (NPRS) for pain intensity $(r=0.95)^{14}$ and the neck disability index (NDI) for functional ability.
Statistical Techniques: Entire statistical calculations was prepared by using SPSS version 20. The variables of qualitative nature were laborated by formulating tables and proportions of frequencies and variables of quantitative nature by means and Standard Deviation (SD). To find out the comparative difference of variables having quantitative nature was measured by applying independent sample " $\mathrm{T}$ " test with extension of Levene's test. P-value $\leq 0.05$ was taken as significant.

\section{Results}

Age of Patients: The mean and standard deviation (SD) of First Group (Maitland Thoracic spine manipulation) and second Group (Maitland cervical spine mobilization) was calculated as $47.04 \pm 5.65$ years and 0.9213 respectively.

Age of the Patient

\begin{tabular}{|c|c|c|c|}
\hline Frequency & Percent & $\begin{array}{c}\text { Valid } \\
\text { Percent }\end{array}$ & $\begin{array}{c}\text { Cumulative } \\
\text { Percent }\end{array}$ \\
\hline 6 & 6.0 & 6.0 & 6.0 \\
\hline 18 & 18.0 & 18.0 & 24.0 \\
\hline 32 & 32.0 & 32.0 & 56.0 \\
\hline 44 & 44.0 & 44.0 & 100.0 \\
\hline 100 & 100.0 & 100.0 & \\
\hline
\end{tabular}

Gender Distribution: Out of hundred patients, First group contains 29 males and 21 females and Second group contains 34 males and 16 females. In hundred

Table 1: Group statistics for NPRS.

\begin{tabular}{|l|l|c|c|c|c|}
\hline & Groups of treatment & $\mathrm{N}$ & Mean & Std. Deviation & Std. Error Mean \\
\hline \multirow{2}{*}{$\begin{array}{l}\text { NPRS values } \\
\text { before treatment }\end{array}$} & Group 1 (Manipulation) & 50 & 3.4800 & .70682 & .09996 \\
\cline { 2 - 7 } & Group 2 (Mobilization) & 50 & 3.6200 & .49031 & .06934 \\
\hline $\begin{array}{l}\text { NPRS Values } \\
\text { after two weeks }\end{array}$ & Group 1 (Manipulation) & 50 & 2.4000 & .75593 & .10690 \\
\cline { 2 - 7 } & Group 2 (Mobilization) & 50 & 3.2800 & .67128 & .09493 \\
\hline $\begin{array}{l}\text { NPRS Values } \\
\text { after four weeks }\end{array}$ & Group 1 (Manipulation) & 50 & 1.3600 & .69282 & .09798 \\
\cline { 2 - 7 } & Group 2 (Mobilization) & 50 & 2.1800 & .82536 & .11672 \\
\hline
\end{tabular}


Table 2: Independent T-test.

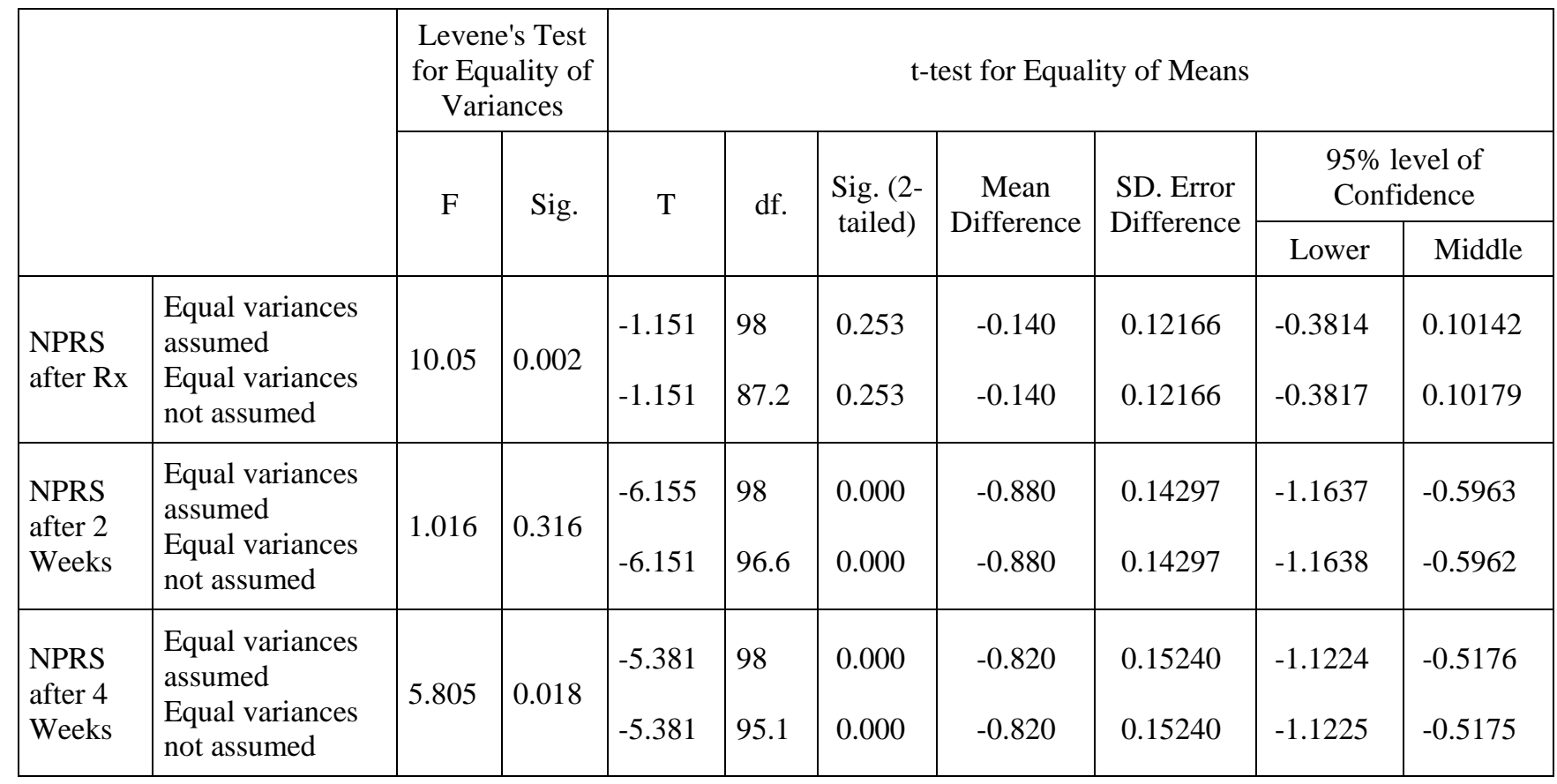

patients, total 63 males (63 percent) and 37 females (37 percent) contributed in the study.

\section{Interpretation for NPRS}

Group A (Maitland Thoracic Spine Manipulation), presented mean pain score on NPRS before treatment $3.4800(\mathrm{SD}=0.7068)$, where as in group B (Maitland Cervical Spine Mobilization) presented mean score on NPRS before treatment 3.6200 (SD = 0.49031 ), and after four weeks of treatment group A presented mean score on NPRS is 1.3600 ( $\mathrm{SD}=0.0979)$, whereas patients in group B presented mean score on NPRS after four weeks of treatment was 2.1800

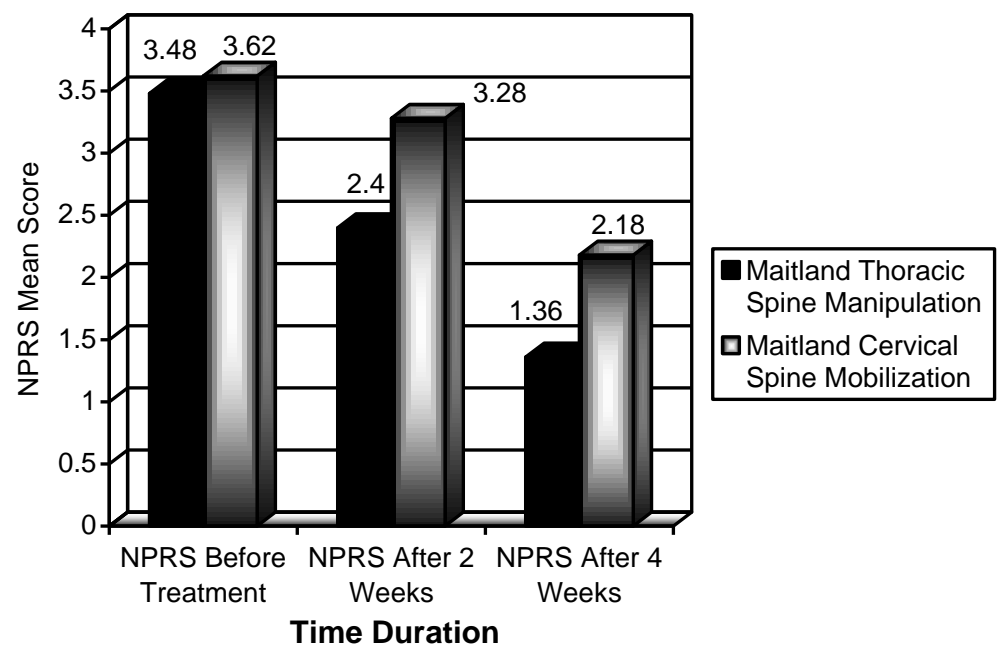
$(\mathrm{SD}=0.8253)$ The results show that there is a statistically significant difference between the mean NPRS post treatment scores and NPRS pretreatment score $(\mathrm{t}=-5.381, \mathrm{p}=.000)$. Both groups verified significant levels of betterment in pain intensity $(\mathrm{P}<$ $0.000)$, at the end of 4 th week treatment points $(\mathrm{P}<$ 0.000 ). As $p=0.000$ is less than 0.05 so we will reject our null hypothesis and accept research hypothesis. So Maitland thoracic spine manipulation treatment protocol is more effective than Maitland cervical spine mobilization.

Graph 1: Numeric Pain Rating Scale.

\section{Interpretation for NDI:}

Group A (Maitland Thoracic Spine Manipulation), presented mean disability index score on NDI before treatment $3.4000(\mathrm{SD}=0.8806)$, where as in group $\mathrm{B}$ (Maitland Cervical Spine Mobilization) presented mean score on NDI before treatment 3.7800 (SD = 0.7082). After four weeks of treatment group A presented mean score of neck disability index 1.5600 $\mathrm{SD}=0.9011$ ), while patients in group $\mathrm{B}$ presented mean score of neck disability index 2.7400 (SD = 
Table 3: Group statistics for NDI.

\begin{tabular}{|l|l|c|c|c|c|}
\hline & Groups of treatment & $\mathrm{N}$ & Mean & Std. Deviation & Std. Error Mean \\
\hline \multirow{2}{*}{ NDI scores before Rx } & Group 1 (Manipulation) & 50 & 3.4000 & .88063 & .12454 \\
\cline { 2 - 6 } & Group 2 (Mobilization) & 50 & 3.7800 & .70826 & .10016 \\
\hline \multirow{2}{*}{ NDI scores after two weeks } & Group 1 (Manipulation) & 50 & 2.8800 & .89534 & .12662 \\
\cline { 2 - 6 } & Group 2 (Mobilization) & 50 & 3.6800 & .58693 & .08300 \\
\hline \multirow{2}{*}{ NDI score after four weeks } & Group 1 (Manipulation) & 50 & 1.5600 & .90711 & .12829 \\
\cline { 2 - 6 } & Group 2 (Mobilization) & 50 & 2.7400 & .89921 & .12717 \\
\hline
\end{tabular}

Table 4: Independent $\mathrm{T}$ test for NDI.

\begin{tabular}{|c|c|c|c|c|c|c|c|c|c|c|}
\hline & \multicolumn{2}{|c|}{$\begin{array}{c}\text { Levene's Test } \\
\text { for Equality of } \\
\text { Variances }\end{array}$} & \multicolumn{7}{|c|}{ t-test for Equality of Means } \\
\hline & & \multirow[t]{2}{*}{$\mathrm{F}$} & \multirow[t]{2}{*}{ Sig. } & \multirow[t]{2}{*}{$\mathrm{t}$} & \multirow[t]{2}{*}{ df. } & \multirow[t]{2}{*}{$\begin{array}{l}\text { Sig. (2- } \\
\text { tailed) }\end{array}$} & \multirow[t]{2}{*}{$\begin{array}{c}\text { Mean } \\
\text { Difference }\end{array}$} & \multirow[t]{2}{*}{$\begin{array}{l}\text { SD. Error } \\
\text { Difference }\end{array}$} & \multicolumn{2}{|c|}{$\begin{array}{l}95 \% \text { Confidence } \\
\text { Interval of the } \\
\text { Difference }\end{array}$} \\
\hline & & & & & & & & & Lower & Middle \\
\hline $\begin{array}{l}\text { NDI } \\
\text { after Rx }\end{array}$ & $\begin{array}{l}\text { Equal variances } \\
\text { assumed } \\
\text { Equal variances } \\
\text { not assumed }\end{array}$ & 3.711 & 0.057 & $\begin{array}{l}-2.378 \\
-2.378\end{array}$ & $\begin{array}{l}98 \\
93.7\end{array}$ & $\begin{array}{l}0.019 \\
0.019\end{array}$ & $\begin{array}{l}-0.380 \\
-0.380\end{array}$ & $\begin{array}{l}0.1598 \\
0.1598\end{array}$ & $\begin{array}{l}-0.6972 \\
-0.6973\end{array}$ & $\begin{array}{l}-0.06284 \\
-0.62660\end{array}$ \\
\hline $\begin{array}{l}\text { NDI } \\
\text { after } 2 \\
\text { Week }\end{array}$ & $\begin{array}{l}\text { Equal variances } \\
\text { assumed } \\
\text { Equal variances } \\
\text { not assumed }\end{array}$ & 8.359 & 0.005 & $\begin{array}{l}-5.284 \\
-5.284\end{array}$ & $\begin{array}{l}98 \\
84.5\end{array}$ & $\begin{array}{l}0.000 \\
0.000\end{array}$ & $\begin{array}{l}-0.800 \\
-0.800\end{array}$ & $\begin{array}{l}0.1514 \\
0.1514\end{array}$ & $\begin{array}{l}-1.1004 \\
-1.1010\end{array}$ & $\begin{array}{l}-0.49955 \\
-0.49895\end{array}$ \\
\hline $\begin{array}{l}\text { NDI } \\
\text { after } 4 \\
\text { Week }\end{array}$ & $\begin{array}{l}\text { Equal variances } \\
\text { assumed } \\
\text { Equal variances } \\
\text { not assumed }\end{array}$ & 0.015 & 0.902 & $\begin{array}{l}-6.533 \\
-6.533\end{array}$ & $\begin{array}{l}98 \\
97.9\end{array}$ & $\begin{array}{l}0.000 \\
0.000\end{array}$ & $\begin{array}{l}-1.180 \\
-1.180\end{array}$ & $\begin{array}{l}0.1806 \\
0.1806\end{array}$ & $\begin{array}{l}-1.5385 \\
-1.5385\end{array}$ & $\begin{array}{l}-0.82154 \\
-0.82154\end{array}$ \\
\hline
\end{tabular}

0.8992). The results indicate that there is a statistically significant difference between the mean NDI post treatment score and NDI pretreatment score $(\mathrm{t}=$ $6.533, \mathrm{p}=.000)$. As $\mathrm{p}=0.000$ is less than $\mathrm{p}=0.05$ so we will reject our null hypothesis and accept research hypothesis. So Maitland thoracic spine manipulation treatment protocol is more effective than Maitland cervical spine mobilization in treating $\mathrm{C}_{6}-\mathrm{C}_{7}$ chronic UCR.

\section{Discussions}

Cervical Radiculopathy can be treated by multiple hysical therapy procedures. Growing documentation of facts suggest that $\mathrm{CR}$ with proper diagnosis might have advantages from a holistic treatment regime that comprises manual physiotherapy, MICT and SE protocols. The endeavor of this research was to see comparison of MTSM versus MCSM for treatment of chronic unilateral $\mathrm{C}_{6}$ and $\mathrm{C}_{7}$ cervical UCR in the means of efficacy. The Consequences of this study show that there is marked reduction in pain and betterment of functional abilities in subjects with chronic $\mathrm{C}_{6}$ and $\mathrm{C}_{7} \mathrm{UCR}$ at the completion of $4^{\text {th }}$ week. $^{11}$

Each of the two groups showed satisfactory results in terms of pain or symptoms relief and functional abi- 
lities at the completion of forth week. A noteworthy reduction in the nature of pain as assessed by NPRS and functional ability as assessed by NDI between two groups but first group with MTSM had shown marked progress in terms of pain lessening and functional disability. ${ }^{11}$

There is a strong association between injuries and discomforts of the thoracic spine with neck ache and GH joint. Instant gain in $\mathrm{ROM}$ and reduction in pain was seen in the cases of neck ache by applying MTSM. For upper limb nerve tension, cervical gliding procedures have best consequences. A motivating thing was that two opposite treatments like MTSM and MCSM having almost same consequences. ${ }^{3}$

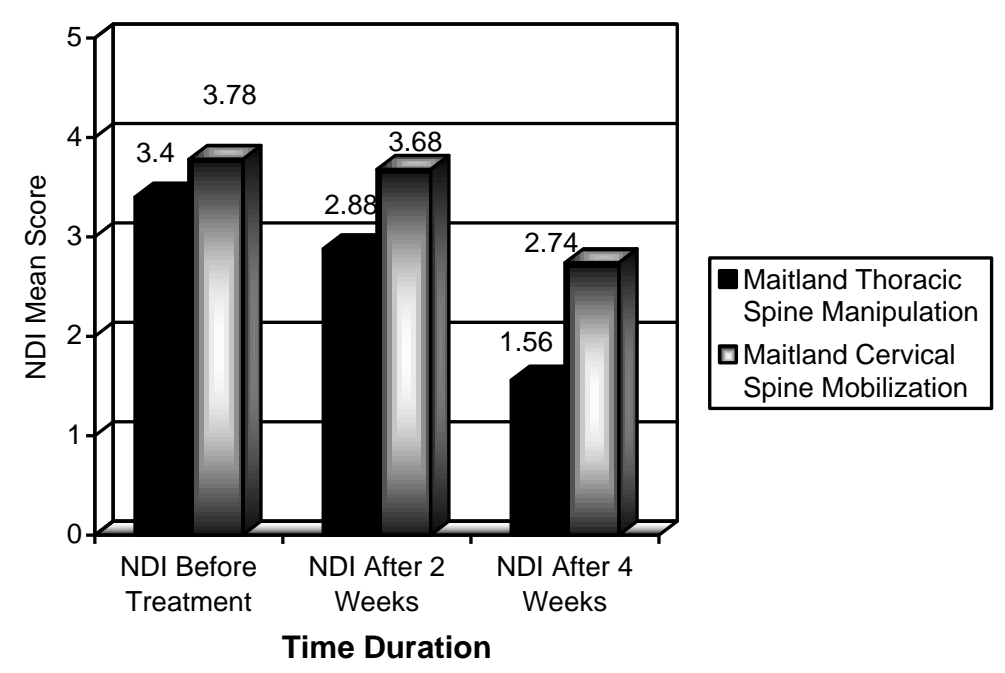

The present study had explored that both, MTSM and MCSM were equally effective in minimizing discomfort and Functional abilities status but MTSM was known as more dedicated and authentic protocol for the subjects suffering from chronic $\mathrm{C}_{6}$ and $\mathrm{C}_{7} \mathrm{UCR}$. So, these techniques can be applied in clinical settings with old protocols for the best and long lasting progresses.

\section{Conclusion and Recommendations}

The results of this study shows that Maitland thoracic spine manipulation and Maitland cervical spine mobilization are both effective in minimizing neck pain with radiation and functional status of patient with chronic unilateral $\mathrm{C}_{6}-\mathrm{C}_{7}$ cervical radiculopathy but on the behalf of comparison, MTSM is more beneficial than MCSM in terms of improvement in pain and disturbed functional status. So the additional and further recommendations for coming studies require to be done with large number of patients and longer follow ups. Future studies can be taken up by using the same interventional techniques and parameters for other conditions.

\section{References}

1. Carette S, Fehlings MG. Cervical radiculopathy. New England Journal of Medicine, 2005; 353 (4): 392-9.

2. Cleland JA, Fritz JM, Whitman JM, Palmer JA. The reliability and construct validity of the Neck Disability Index and patient specific functional scale in patients with cervical radiculopathy. Spine, 2006; 31 (5): 598-

3. Bono CM, Ghiselli G, Gilbert TJ, Kreiner DS, Reitman C, Summers JT, et al. An evidence - based clinical guideline for the diagnosis and treatment of cervical radiculopathy from degenerative disorders. The Spine Journal, 2011; 11 (1): 64-72.

4. Jellad A, Salah ZB, Boudokhane S, Migaou H, Bahri I, Rejeb N. The value of intermittent cervical traction in recent cervical radiculopathy. Annals of physical and rehabilitation medicine, 2009; 52 (9): 638-52.

5. Cleland JA, Whitman JM, Fritz JM, Palmer JA. Manual physical therapy, cervical traction, and strengthening exercises in patients with cervical radiculopathy: a case series. Journal of Orthopaedic and Sports Physical Therapy, 2005; 35 (12): 802-11.

6. Young IA, Michener LA, Cleland JA, Aguilera AJ, Snyder AR. Manual therapy, exercise, and traction for patients with cervical radiculopathy: a randomized clinical trial. Physical Therapy, 2009; 89 (7): 632-42.

7. Inderpreet K, Arunmozhi R, Umer A. Effect of Maitland vs Mulligan Mobilisation Technique on Upper Thoracic Spine in Patients with Non-Specific Neck Pain - A Comparative Study. Int J Physiother Res. 2013; 1 (5): 214-18.

8. Rodine RJ, Vernon H. Cervical radiculopathy: a systematic review on treatment by spinal manipulation and measurement with the Neck Disability Index. The Journal of the Canadian Chiropractic Association, 2012; 56 (1): 18.

9. Jiang C, Wang J, Zheng Z, Hou J, Ma L, Sun T. Efficacy of cervical fixed - point traction manipulation for cervical spondylotic radiculopathy: a randomized controlled trial]. Zhong xi yi jie he xue bao. Journal of Chinese integrative medicine, 2012; 10 (1): 54-8.

10. Boyles R, Toy P, Mellon Jr J, Hayes M, Hammer B. 
Effectiveness of manual physical therapy in the treatment of cervical radiculopathy: a systematic review. Journal of Manual and Manipulative Therapy, 2011; 19 (3): 135-42.

11. Gopal Nambi S, Vora PK, Jhang M. Cervical spine mobilization versus Thoracic spine manipulation in subjects with unilateral $\mathrm{C}_{6}$ and $\mathrm{C}_{7}$ Cervical Radiculopathy - Comparative study.

12. Gross A, Miller J, D'Sylva J, Burnie SJ, Goldsmith CH,
Graham N, et al. Manipulation or mobilisation for neck pain: a Cochrane Review. Manual therapy, 2010; 15 (4): 315-33.

13. Williamson A, Hoggart B. Pain: a review of three commonly used pain rating scales. Journal of clinical nursing, 2005; 14 (7): 798-804.

14. Hartrick CT, Kovan JP, Shapiro S. The numeric rating scale for clinical pain measurement: a ratio measure? Pain Practice, 2003; 3 (4): 310-6. 